\title{
Applying a Mathematical Model to the Performance of a Female Monofin Swimmer
}

\author{
Elisée Gouba ${ }^{1}$, Balira Ousmane Konfe ${ }^{2}$, Ousseynou Nakoulima ${ }^{3}$, Blaise Some ${ }^{1}$, Olivier Hue ${ }^{4}$ \\ ${ }^{1}$ Laboratoire LANIBIO, U.F.R. S.E.A., Université de Ouagadougou, \\ Ouagadougou, Burkina Faso \\ ${ }^{2}$ Laboratoire LAIMA, Institut Africain d'Informatique, Libreville, Gabon \\ ${ }^{3}$ Département de Mathématiques et Informatique, Université Antilles-Guyane, \\ Pointe-à-Pitre, France \\ ${ }^{4}$ Laboratoire A.C.T.E.S., UPRES-EA 3596, U.F.R. S.T.A.P.S.-U.A.G., \\ Faculté de Médecine, Pointe-à-Pitre, France \\ Email: elgouba@gmail.com,obalira@yahoo.fr, onakouli@univ-ag.fr, some@univ-ouaga.bf, ohue@univ-ag.fr
}

Received March 6, 2013; revised April 6, 2013; accepted April 13, 2013

Copyright (C) 2013 Elisée Gouba et al. This is an open access article distributed under the Creative Commons Attribution License, which permits unrestricted use, distribution, and reproduction in any medium, provided the original work is properly cited.

\begin{abstract}
This study sought to determine the best method to quantify training based on heart rate data. It proposes a modification of Banister's original performance model to improve the accuracy of predicted performance. The new formulation introduces a variable that accounts for changes in the subject's initial performance as a result of the quantity of training. The two systems models were applied to a well-trained female monofin swimmer over a 24-week training period. Each model comprised a set of parameters unique to the individual and was estimated by fitting model-predicted performance to measured performance. We used the Alienor method associated to Optimization-Preserving Operators to identify these parameters. The quantification method based on training intensity zones gave a better estimation of predicted performance in both models. Using the new model in sports in which performance is generally predicted (running, swimming) will help us to define its real interest.
\end{abstract}

Keywords: Training Quantification; Banister's Model

\section{Introduction}

In 1975, Banister et al. [1-4] proposed a systems model to predict athletic performance. This model (and its extensions) is based on two antagonistic functions: the positive function can be compared to a fitness impulse resulting from the organism's adaptation to training and the negative function is similar to a fatiguing impulse. Each function comprises a set of parameters that are interpreted as the individual's response profile, which can be used for training prescription. Parameters include, for example, time to recover performance and time to peak performance after training completion.

Monofin swimming is a relatively new sport (recognized by the IOC in 1986) that consists of propelling the body at the water surface or underwater with an undulation accentuated by the monofin $[5,6]$. Very high swim velocities can thereby be reached (up to $14 \mathrm{~km} \cdot \mathrm{h}^{-1}$ ), and this sport is attracting a growing number of enthusiasts. Although a few studies have investigated the techniques of monofin swimming [5,7-9], little is actually known about fin swimmers and the parameters that contribute to performance. In 2005, O. Hue et al. found that both anthropometric and physiological (aerobic and anaerobic components) factors contributed to the performances of French West Indian monofin swimmers. The finding that both maximal oxygen uptake and the second ventilatory threshold were significantly correlated with performance [10], suggested that monofin swimming performance, like running [11,12], swimming [13,14] and cycling [15], could be extrapolated using Banister's model. However, this model had been criticized by several authors [16-19] who reported that the practical interpretation of the positive and negative influences might be difficult. For example, Taha and Thomas [19] criticized the models stemming from Banister's original model [13], stressing their inability to accurately predict future performance, the difference between the estimated time course of performance changes and experimental observations, and the fact 
that most of these models were poorly corroborated by physiological mechanisms.

In Banister's model, performance is mathematically related to the training load using any one of the three basic methods of training quantification: a method using the mathematical formula developed by Banister and Hamilton [20], another using the three intensity zones defined by the aerobic and anaerobic ventilatory thresholds, and the last using five intensity zones. Although several authors have used one or another method to quantify training without providing justification (for example [21-23] used the mathematical formula; and [12, $14,24]$ used the training quantification method with five intensity zones), we cannot rule out the possibility that using various training quantification methods may affect the accuracy of performance prediction with Banister's model.

Our main objectives in this study of an internationally ranked monofin swimmer were the followings: 1) to determine the best method of quantifying training that provides a pertinent model over a 24 -week training period and for each time that performance is measured; and 2) to propose a new model based on Banister's original model that would improve the accuracy of predicting performance.

\section{Methods}

\subsection{Subject}

A 17-year-old female monofin swimmer, weighing $64 \mathrm{~kg}$ for $164 \mathrm{~cm}$, was recruited. The subject had previous competitive swimming experience and at the time of the study was among the top 15 monofin swimmers in the Junior World ranking. The subject was fully informed of the study conditions and gave written consent in accordance with the regional ethics committee before participating.

\subsection{The Progressive and Maximal Exercise Test}

The ramp exercise test began with a 3-minute warm-up at $30 \mathrm{~W}$, and the load was increased by $15 \mathrm{~W}$ every minute until exhaustion. Pedaling speed remained constant at 70 rpm during the entire test.

Gas exchanges were measured during the first and third repetitions using a breath-by-breath automated exercise metabolic system (Zan 680, Zan, Oberthulba, Germany) and oxygen uptake was considered maximal (i.e., $\mathrm{VO}_{2 \max }$ ) if at least three of the following four criteria were met:

1) a respiratory exchange ratio greater than 1.10 ,

2) attainment of age-predicted maximal heart rate $\left(\mathrm{HR}_{\max }\right)[210-(0.65 \times \mathrm{age}) \pm 10 \%]$,

$3)$ an increase in oxygen uptake $\left(\mathrm{VO}_{2}\right)$ lower than 100 $\mathrm{ml}$ with the last increase in work rate, and
4) an inability to maintain the required pedaling frequency $(70 \mathrm{rpm})$ despite maximum effort and verbal encouragement. The heart rate at rest $\left(\mathrm{HR}_{\mathrm{rest}}\right)$ and the maximal aerobic power (MAP) were also determined. A 10lead electrocardiogram (12-lead ECG, Del Mar Deynolds, Spacelabs, Healthcare Inc., UK) was used to monitor heart rate continuously. The results are shown in Table 1.

\subsection{Ventilatory Threshold Determination}

The ventilatory thresholds were visually determined according to the method of Wasserman et al. [25,26], which describes the inflection points in pulmonary ventilation during incremental exercise. The ventilatory thresholds (VTs) were identified when breakpoints occurred in the $\mathrm{VE} / \mathrm{VO}_{2}$ and $\mathrm{VE} / \mathrm{VCO}_{2}$ curves. The first ventilatory threshold (VT1) was identified by the point of non-linear increase in $\mathrm{VE}$ and a clear increase in $\mathrm{VE} / \mathrm{VO}_{2}$. At the same time, $\mathrm{VE} / \mathrm{VCO}_{2}$ remained constant or slightly decreased. VT1 was also determined by the V-slope method of [27], which consisted of plotting $\mathrm{VCO}_{2}$ against $\mathrm{VO}_{2}$ to identify a steep rise in $\mathrm{VCO}_{2}$ compared with the rise in $\mathrm{VO}_{2}$ with increasing intensity. The second ventilatory threshold (VT2), which corresponds to the respiratory decompensation for metabolic acidosis, was identified by a second non-linear increase in VE and a second clear increase in $\mathrm{VE} / \mathrm{VO}_{2}$. At this point, $\mathrm{VE}$ rose more rapidly than $\mathrm{VCO}_{2}$, leading to a rise in $\mathrm{VCO}_{2}$. Three experienced investigators independently deter- mined these thresholds (Table 1).

\subsection{Experimental Design}

During a 24-week period, the subject continued her regular training regime and recorded details of each training session. In addition, she completed performance tests and fatigue questionnaires. The performance tests were not conducted during periods of national or international competition.

\subsection{Fatigue Questionnaire}

Before each performance test, the subject completed the original version of the Profile of Mood States (POMS) questionnaire developed in 1971 by McNair, Lorr \& Droppleman [28]. The subject used a 5-point scale $(0=$ "not at all" to $4=$ "extremely") to respond to each item. In the present study, only the responses to the fatigue subset of the POMS were considered.

\subsection{Performance Test}

Performance tests over a distance of $700 \mathrm{~m}$ were made every three weeks. During training sessions and performance tests, the subject wore a heart rate monitor 
Table 1. Physiological performance obtained for the subject.

\begin{tabular}{ccccccccc}
\hline $\mathrm{VO}_{2} \mathrm{max}$ & $\mathrm{VT} 1$ & $\mathrm{VT} 2$ & $\mathrm{MAP}$ & $\mathrm{MAP}(\mathrm{VT} 1)$ & $\mathrm{MAP}(\mathrm{VT} 2)$ & $\mathrm{HR}_{\max }$ & $\mathrm{HR}(\mathrm{VT} 1)$ & $\mathrm{HR}(\mathrm{VT} 2)$ \\
\hline $\mathrm{ml} \cdot \mathrm{min}^{-1} \cdot \mathrm{kg}^{-1}$ & $\% \mathrm{VO}_{2} \max$ & $\% \mathrm{VO}_{2} \mathrm{max}$ & watts & watts & watts & $\mathrm{bpm}$ & $\mathrm{bpm}$ & $\mathrm{bpm}$ \\
45.5 & 61.5 & 82.1 & 232 & 151 & 202 & 194 & 155 & 181 \\
\hline
\end{tabular}

$\mathrm{VO}_{2} \mathrm{max}$, maximal oxygen uptake; VT1, ventilatory threshold; VT2, respiratory compensation threshold; MAP, maximal aerobic power (power attained at $\mathrm{VO}_{2} \mathrm{max}$ ); $\mathrm{HR}_{\max }$, maximal heart rate; MAP (VT1), maximal aerobic power at VT1; HR (VT1), heart rate corresponding to VT1.

(Polar S810i, Polar Electro, Kempele, Finland) that recorded heart rate every $5 \mathrm{~s}$. The heart rate data for each exercise bout was analyzed using Polar Precision software.

\section{Training Quantification}

The exercise training intensity can be quantified using several methods based on heart rate or lactate response, the expression of intensity relative to maximum heart rate or oxygen consumption, or the expression of intensity relative to ventilation or the anaerobic threshold. However, only the subset of methods generally used in training-performance modeling were studied.

For each exercise session, training impulse (TRIMP) was quantified three ways (Figure 1):

- With the mathematical formula developed by Banister and Hamilton [20],

- Based on a repartition of heart rate into three zones of intensity [29],

- Based on a breakdown of heart rate into five zones of intensity [14].

\subsection{Mathematical Formula}

The mathematical formula is given by:

$$
w(t)=d \times k \times x
$$

where $d$ is the exercise duration expressed in minutes, $x$ is defined by:

$$
x=\frac{H R_{\text {exercise }}-H R_{\text {rest }}}{H R_{\text {max }}-H R_{\text {rest }}}
$$

and $k$ is related to the subject's gender; in our study, the subject was female, thus

$$
k=0.86 \times \mathrm{e}^{1.67 x}
$$

Here $H R_{\text {rest }}$ indicates the lowest measure of heart rate recorded when the subject is awake and $H R_{\max }$, the highest recorded during incremental testing on a cycle ergometer.

\subsection{Training Quantification with Three Intensity Zones}

The three intensity zones were defined taking into account the HR corresponding to the ventilatory thresholds.
Zone 1 includes all HR below the first ventilatory threshold, zone 2 contains the HR between the two thresholds, and zone 3 includes all HR above the second threshold.

The amount of training in each zone is equal to the exercise duration in minutes in this area, multiplied by the physiological stress weighting factor for that intensity zone (zone $1 \rightarrow 1$, zone $2 \rightarrow 2$, zone $3 \rightarrow 3$ ). The training impulse for each exercise bout was thus recorded as the sum of the training impulse scores for each intensity zone.

\subsection{Training Quantification with Five Intensity Zones}

The five intensity zones were defined according to the study of Wood et al. [12]. The physiological stress weighting factor used for each training intensity zone has been reported elsewhere [14].

Figure 1 present training loads performed by the subject during the course of the study; training loads are quantified with the three methods of training quantification

\section{Modeling of the Response to Training}

We used the model proposed by Banister et al. [13], which considers the athlete as an open system with the training impulse as the input and performance as the output. This type of modeling models "cause" to "effect" phenomena and usually leads directly to integral equations [30].

The time functions of performance $p(t)$ and training load $w(t)$ are mathematically related as

$$
p(t)=p_{0}+(p * g)(t)
$$

where $p_{0}$ is an additive term that depends on the initial training status of the subject and $*$ denotes the product of convolution. $g$ is a transfer function that depends on time and is defined by

$$
g(t)=k_{1} \exp \left(\frac{-t}{\tau_{1}}\right)-k_{2} \exp \left(\frac{-t}{\tau_{2}}\right)
$$

where $k_{1}$ and $k_{2}$ are gain terms and $\tau_{1}$ and $\tau_{2}$ are time constants.

The definition of the convolution product leads to: 


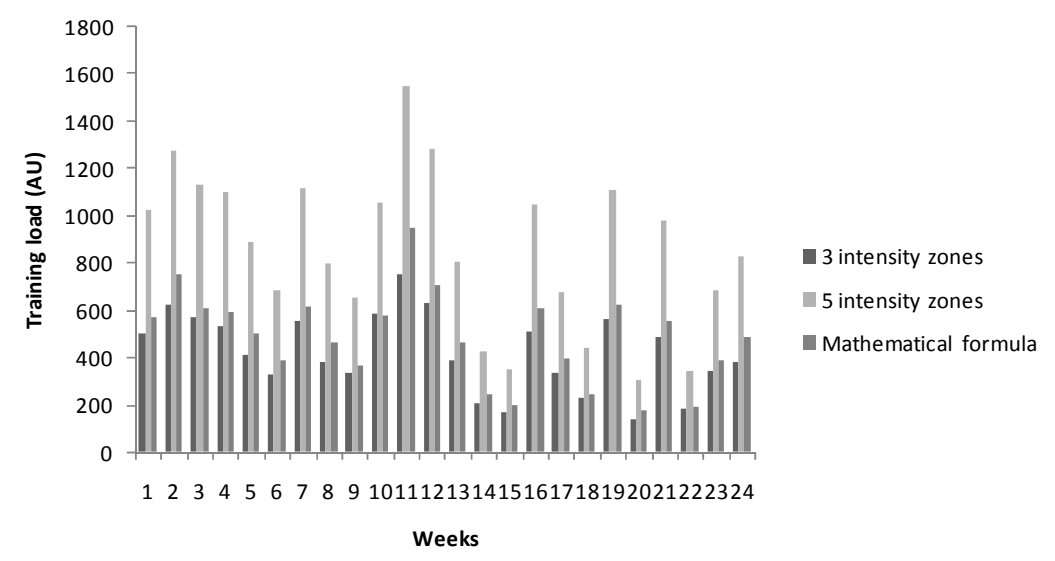

Figure 1. Training loads performed by the subject during the course of the study; training loads are quantified with the three methods of training quantification.

$$
p(t)=p_{0}+\int_{-\infty}^{+\infty} g(s) w(t-s) \mathrm{d} s \quad s \geq 0, t \geq 0
$$

with

$$
g(s)= \begin{cases}k_{1} \exp \left(\frac{-s}{\tau_{1}}\right)-k_{2} \exp \left(\frac{-s}{\tau_{2}}\right) & \text { if } s \geq 0 \\ 0 & \text { otherwise }\end{cases}
$$

and

$$
w(t-s)=0 \quad \text { if } s \geq t
$$

Then

$$
\begin{gathered}
p(t)=p_{0}+\int_{0}^{t} g(s) w(t-s) \mathrm{d} s \\
p(t)=p_{0}+\int_{0}^{t} w(s) g(t-s) \mathrm{d} s
\end{gathered}
$$

Time discretization of (4) using the composite trapezoid rule gives an estimation of the model performance on day $n, p_{n}$, from the successive training loads $w_{i}$ with $i$ varying from 1 to $n-1$. Thus

$$
p_{n}=p_{0}+k_{1} \sum_{i=1}^{n-1} w_{i} \exp \left(\frac{-(n-i)}{\tau_{1}}\right)-k_{2} \sum_{i=1}^{n-1} w_{i} \exp \left(\frac{-(n-i)}{\tau_{2}}\right)
$$

In (5), $p_{0}$ appears as a constant during the study, although it is known that performance varies with the quantity of training. For this, we here propose a modified Banister model, with performance on day $n$ based on previous performance. Mathematically, we have for $j \geq 1$

$$
\begin{aligned}
p_{n}^{j}= & p^{j-1}+k_{1} \sum_{i=1}^{n-1} w_{i} \exp \left(\frac{-\left(n_{j}-i\right)}{\tau_{1}}\right) \\
& -k_{2} \sum_{i=1}^{n-1} w_{i} \exp \left(\frac{-\left(n_{j}-i\right)}{\tau_{2}}\right)
\end{aligned}
$$

where $j$ is the number of performances measured and $n_{j}$, the number of training loads between performances $p^{j-1}$ and $p^{j}$.

\section{Fitting the Model}

The model parameters are unique to the individual and were evaluated by minimizing the residual sum of square (RSS) between the real and modeled performances:

$$
R S S=\sum_{j=1}^{N}\left|p_{n}^{j}-p^{j}\right|^{2}
$$

where $N$ is the number of real performances. RSS is a non-linear function; we first used the Alienor method and $\mathrm{OPO}^{*}$ [31] to identify $k_{1}, k_{2}, \tau_{1}$ and $\tau_{2}$. Computations were completed using Maple 12 software.

\section{Calculation of $t_{n}$ and $t_{g}$}

The time to recover performance $t_{n}$ was calculated by resolution of the equation $g(t)=0$; we obtained

$$
t_{n}=\frac{\tau_{1} \tau_{2}}{\tau_{1}-\tau_{2}} \ln \left(\frac{k_{2}}{k_{1}}\right)
$$

The time to peak performance after training completion $t_{g}$, was obtained by resolution of the equation $g^{\prime}(t)=0$; we obtained

$$
t_{n}=\frac{\tau_{1} \tau_{2}}{\tau_{1}-\tau_{2}} \ln \left(\frac{\tau_{1} k_{2}}{\tau_{2} k_{1}}\right)
$$

\section{Statistical Analysis}

The coefficient of determination $\left(R^{2}\right)$ gave the percent variation explained by the model and was calculated to establish the goodness of fit for the model. The statistical significance of this fit was assessed by an analysis of variance on the residuals with associated degrees of freedom. Statistical significance was accepted if 
$p \leq 0.05$. The correlations between modeled fatigue and the corresponding POMS fatigue subset scores were analyzed using the Pearson product-moment correlation coefficient. All statistical analysis was completed using statistical software $R$.

\section{Results}

The coefficient of determination $R^{2}$ was equal to 0.28 for Banister's model and 0.38 for the alternative model (Figure 2). The values for $\tau_{1}$ and $\tau_{2}$ were 42.25 days and 15.29 days, respectively. The weighting factors, $k_{1}$ and $k_{2}$, were 0.00001083 and 0.000015 respectively. The time needed after training impulse for the effects of fatigue to be dissipated sufficiently to allow the effects of training to return performance to the pretraining level $t_{n}$ was 7.81 days, and the time needed to reach maximal performance after training impulse $t_{g}$ was 32.17 days. Using the fatigue subset of the POMS questionnaire, the athlete reported substantial fluctuations in fatigue status across the training period [12]. The fatigue scores in this study ranged from 2 to 13 on the 28 -point scale. The fit between the fatigue component of the model and the
POMS fatigue subset score gave $R^{2}=0.58$ (Figure 3).

Figure 2 shows the relationship between model-predicted and actual performance.

Figure 3 illustrates the relationship between the fatigue component of the model in arbitrary units (AU), and the score from the fatigue subset of the POMS questionnaire.

\subsection{Comparison of the Three Methods of Quantification}

RSS measures the gap between calculated and measured performance; the smaller this difference is, the better the model. Using the three methods of training quantification indiscriminately, we found that they gave the same minimizers, $k_{1}, k_{2}, \tau_{1}$ and $\tau_{2}$ but the minimum of RSS differed depending on the method. We present the results for Banister's model in Table 2.

Mathematically, we can deduce that quantification using three intensity zones was the best method for our study using Banister's model.

With the modified model of Banister, we have the results in Table 3.

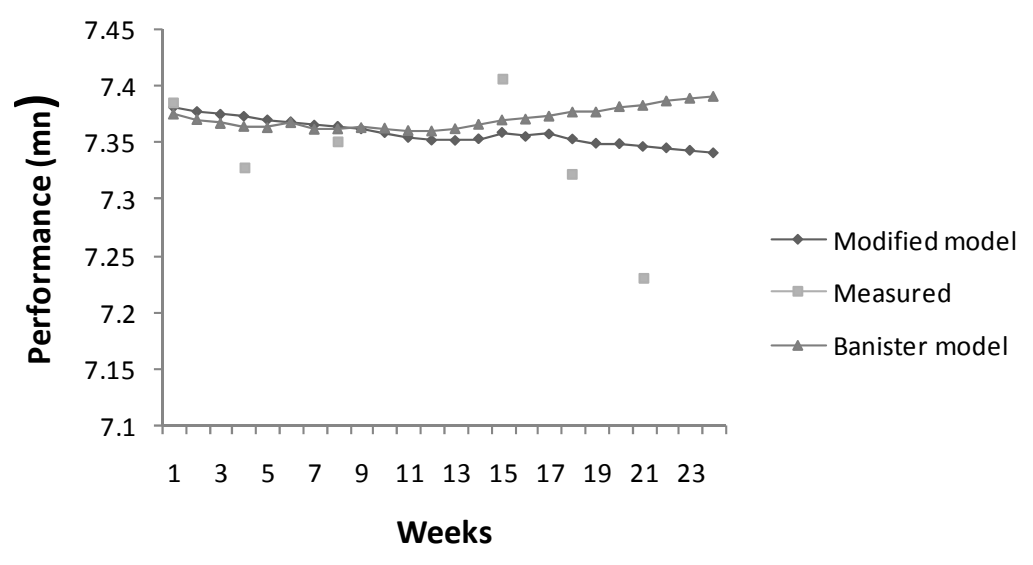

Figure 2. The relationship between model-predicted and actual performance.

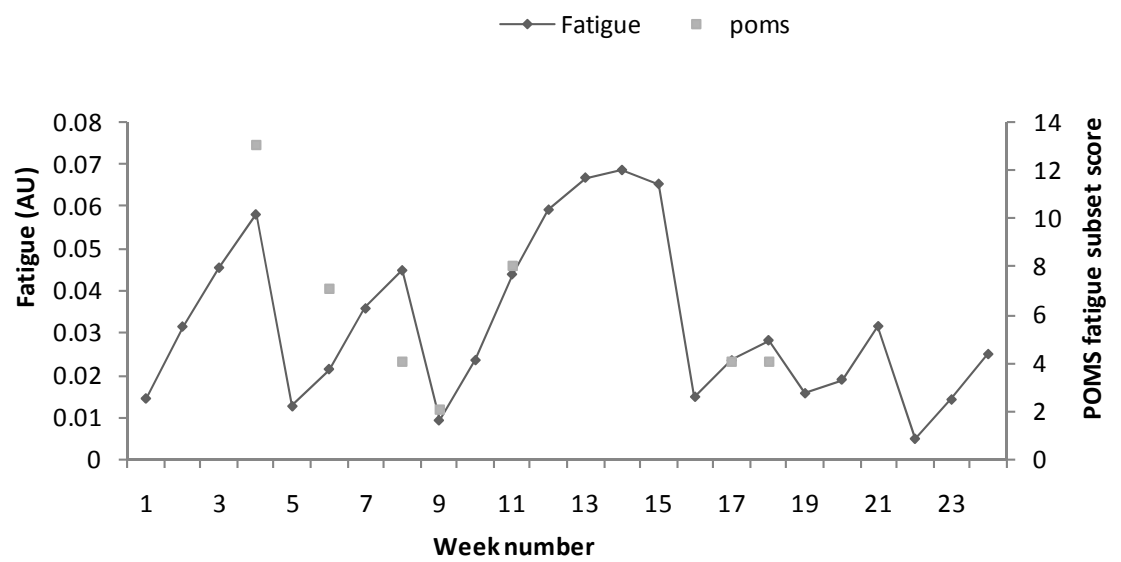

Figure 3. The relationship between the fatigue component of the model in arbitrary units (AU), and the score from the fatigue subset of the POMS questionnaire. 
Table 2. Minimum of RSS assessed with Banister's model from the three methods of training quantification.

\begin{tabular}{cc}
\hline Quantification method & Minimum of $R S S$ \\
\hline Mathematical formula & $\mathbf{0 . 0 3 5 6 4 5}$ \\
Three intensity zones & $\mathbf{0 . 0 3 5 3 7 0}$ \\
Five intensity zones & $\mathbf{0 . 0 3 7 6 1}$ \\
\hline
\end{tabular}

Table 3. Minimum of RSS assessed with the modified model of Banister from the three methods of training quantification.

\begin{tabular}{cc}
\hline Quantification method & Minimum of RSS \\
\hline Mathematical formula & $\mathbf{0 . 0 2 4 0 2 0}$ \\
Three intensity zones & $\mathbf{0 . 0 2 5 0 6 9}$ \\
Five intensity zones & $\mathbf{0 . 0 1 8 6 5 7}$ \\
\hline
\end{tabular}

From a mathematical point of view, training quantifycation using five intensity zones was the best method for this study using the modified model of Banister.

\subsection{Training Quantification and Changes over Time}

In Table 4, we present the results using Banister's model and the modified model according to the number of actual performances measured over time.

\section{Discussion}

The main findings of the present study were:

- The modified model of Banister explains performance better than Banister's model using the three methods of training quantification.

- The method of training quantification plays an important role in predicting performance.

- The choice of training quantification method should be made on the basis of the number of performances that will be measured.

The model parameters in the present study were similar to those reported previously $[11,14,15,18,24]$. The weighting factors $\left(k_{1}\right.$ and $\left.k_{2}\right)$, giving a $k_{2} / k_{1}$ ratio of 1.36 , and the positive and negative time constants ( $\tau_{1}=42.25$ days and $\tau_{2}=15.29$ days ) of the models were within the ranges previously reported. Values for $t_{n}$ and $t_{g}$ were thus also within the reported ranges [14, 21].

The systems model proposed by Banister et al. [13] was reported to account for up to $94 \%$ of the variance in actual performance [16], and $92 \%$ in the study of [12]. In the present study, the variance in modeled performance explained $28 \%$ of the variance in actual performance over a 24-week training period using Banister's model
Table 4. Modified model and Banister model parameters and the minimum of RSS assessed according to the number of performances measured with the quantification of training using five intensity zones.

\begin{tabular}{|c|c|c|c|c|c|}
\hline \multicolumn{6}{|c|}{$\begin{array}{c}\text { Modified } \\
\text { Model }\end{array}$} \\
\hline$N$ & $k_{1}$ & $\tau_{1}$ & $k_{2}$ & $\tau_{2}$ & Min RSS \\
\hline 1 & 0.00160503 & 54.26 & 0.0017181 & 22.28 & 0.00125766 \\
\hline 2 & 0.00160503 & 54.26 & 0.0017181 & 22.28 & 0.0013061 \\
\hline 3 & 0.00001083 & 42.25 & 0.000015 & 15.29 & 0.0049432 \\
\hline 4 & “ & “ & “ & “ & 0.0057478 \\
\hline 5 & “ & “ & “ & “ & 0.0186574 \\
\hline \multicolumn{6}{|c|}{$\begin{array}{c}\text { Banister } \\
\text { Model }\end{array}$} \\
\hline$N$ & $k_{1}$ & $\tau_{1}$ & $k_{2}$ & $\tau_{2}$ & Min RSS \\
\hline 1 & 0.00160503 & 54.26 & 0.0017181 & 22.28 & 0.00125766 \\
\hline 2 & 0.00001083 & 42.25 & 0.000015 & 15.29 & 0.0027070 \\
\hline 3 & “ & “ & “ & “ & 0.0039183 \\
\hline 4 & “ & “ & “ & “ & 0.00833458 \\
\hline 5 & “ & “ & “ & “ & 0.0376192 \\
\hline
\end{tabular}

$N=$ the number of performances measured; $k_{1}$ and $k_{2}=$ the fitness and fatigue magnitude factors, respectively; $\tau_{1}$ and $\tau_{2}=$ the fitness and fatigue decay time constants, respectively.

and $38 \%$ using the alternative model. These relatively poor correlations may be due to the following:

- First, we quantified training during a 24-week training period with only the parameters of the first test of $\dot{\mathrm{VO}}_{2}$ max ; thus the ventilatory thresholds were not adjusted with a second test of $\mathrm{VO}_{2} \max$ (which could have been part of the experimental design). In some studies, ventilatory thresholds [12] or blood lactate testing [14] were repeated during the testing protocol. It has been demonstrated that values of target HR for training orientation generally remain stable in elite endurance athletes [32]. However, because our study was somewhat long, we cannot rule out the possibility that the ventilatory thresholds may have changed during the training period, inducing changes in the performance modeling.

- Second, the number of actual performances (6 for this study) was very low. It takes at least ten actual performances to ensure that the adjustment of performance calculated from the model is statistically significant [17]. However, in real conditions, more than one maximal performance every three weeks seemed unrealistic to us, at least for internationally-ranked athletes who do a lot of traveling for international events. 


\subsection{Modified Model of Banister}

Banister and al. [13] initially proposed modeling the effects of training by quantifying the training and its effects on performance. This model assumed that performance results from a balance between the benefits of work (fitness) and the associated risks (fatigue). As the relationship between the amount of training and performance seems more complex than the relationship assumed by this model, many authors have proposed modified versions of the model. The model we propose here, unlike the original model of Banister, lets the initial performance of the subject vary over time. This model and the original model were applied to the same heart rate data from the subject so that we could compare the two models using the minimum of RSS. Of course, in this case the model that provides the lower value of the minimum of RSS is the better model. Tables 2 and $\mathbf{3}$ showed that our model gave the lower value. For example, with the training quantification method using five zones of intensity, Banister's model gave a minimum RSS value of 0.03761 versus 0.01865 for the modified model; this model provides the same benefits as Banister's model but it signifycantly reduces the residual error. With a good method to quantify training, it could objectify the subject's overall reaction to training.

\subsection{Best Method of Training Quantification}

Training load, which includes the duration and intensity of exercise, can be seen as a reflection of the constraints imposed on the athlete's body. Its calculation is particularly important in performance assessment. The limitations of training load quantification come from the fact that exercise intensity is assessed by heart rate. But the relationship between the actual exercise intensity and HR may be affected by body position [33], fatigue, heat, altitude [34], and the psycho-emotional state of the athlete. Despite these limitations, the use of HR in general remains the best way to quantify training.

We found that training quantification using intensity zones allowed the two models of performance to approach measured performance more closely than with the mathematical formula.

Training quantification using the mathematical formula developed by Banister and Hamilton (1985) is easy (logiperf software R2D2, Paris) and precise. This formula could be improved by taking into account changes in HR at thresholds over the course of training.

\subsection{Best Method of Training Quantification over Time}

The fit of our subject's performances measured throughout the study to the two models is illustrated in Table 4. Table 4 shows once again that the method of training quantification using intensity zones is better; depending on the number of performances measured, three or five intensity zones can be used.

Moreover, this study underlined the importance of performance measurement that is regular and in sufficient numbers (at least 3 ) so that the model parameters unique to the individual reach a certain stability. For example, in Table 4 with the modified model, the parameter $\tau_{1}$ had a value of 54.26 days for the data from one and two measurements of performance and then stabilized at 42.25 days from the third measured performance.

\subsection{Relationship between the Fatigue Component of the Model and the Score from the Fatigue Subset of the Profile of Mood States (POMS) Questionnaire}

The fatigue questionnaire allowed us to closely follow the athlete's reactions to work loads. Previous studies used the POMS questionnaire to track mood changes in athletic populations [35] or to attempt to validate the fatigue component of a model [12]. In the study of Wood et al. [12], the fatigue component of their model accounted for only $56 \%$ of the variance in POMS-measured fatigue during the 12-week training period. Similarly, in the present study the fatigue component of the model accounted for $58 \%$ of the variance in POMS-measured fatigue during the 24-week training period (Figure 3). This relatively poor correlation could be due to several factors: the fatigue component of the model depends only on the training impulse but in reality fatigue is determined by other life factors [12].

\section{Conclusion}

The aim of this study was to determine the best method of training quantification using Banister's model and a modified model of Banister. The results show that the methods using intensity zones provide a good performance fit. The modified version of Banister's original model that is proposed in this study reduced the gap between measured and calculated performance. But, like the original model, it had limitations, indicated by the poor correlations between predicted and real performance. Using this new model in sports in which performance is usually predicted (i.e., running, cycling or swimming) will help us to define its real interest.

\section{REFERENCES}

[1] T. Busso, "Variable Dose-Response Relationship between Exercise Training and Performance," Medicine \& Science in Sports \& Exercise, Vol. 35, No. 7, 2003, pp. 11881195 .

http://dx.doi.org/10.1249/01.MSS.0000074465.13621.37 
[2] T. Busso, C. Denis, R. Bonnefoy, A. Geyssant and J. R. Lacour, "Modeling of Adaptations to Physical Training by Using a Recursive Least Squares Algorithm," Journal of Applied Physiology, Vol. 82, No. 5, 1997, pp. 16851693.

[3] T. Busso, C. Denis, H. Benoît, R. Bonnefoy, L. Feasson and J. R. Lacour, "Effects of Training Frequency on the Dynamics of the Performance Response to a Single Training Bout," Journal of Applied Physiology, Vol. 92, No. 2, 2002, pp. 572-580.

[4] T. W. Calvert, E. W. Banister, M. V. Savage and T. Bach, "Systems Model of the Effect of Training on Physical Performance," IEEE Transactions on Systems, Man, and Cybernetics, Part B, Vol. 6, No. 2, 1976, pp. 94-102.

[5] L. Baly, D. Favier and A. Durey, "Finswimming Technical Description by 3D Kinematic Study," Archives of Physiology and Biochemistry, Vol.109, No. 1, 2001, p. 67.

[6] R. H. Sanders, J. M. Cappaert and R. K. Devlin, "Waves Characteristics of Butterfly Swimming," Journal of Biomechanics, Vol. 28, No. 1, 1995, pp. 9-16.

http://dx.doi.org/10.1016/0021-9290(95)80002-6

[7] J. Gautier, L. Baly, P. R. Zanone and B. Watier, "A Kinematic Study of Finswimming at Surface," Journal of Sports Science and Medicine, Vol. 3, No. 2, 2004, pp. 9195.

[8] M. A. Luersen, R. Leriche, D. Lemosse and O. A. Lemaître, "A Computationally Efficient Approach to Swimming Monofin Optimization," Structural and Multidisciplinary Optimization, Vol. 31, No. 6, 2006, pp. 488-496. http://dx.doi.org/10.1007/s00158-006-0001-6

[9] R. Marek and B. Grazyna, "Searching for Criteria in Evaluating the Monofin Swimming Trun from the Perspective of Coaching and Improvement Technique," Journal of Sports Science and Medicine, Vol. 7, No. 1, 2008, pp. 67-77.

[10] O. Hue, O. Galy, S. Blonc and C. Hertogh, "Anthropometrical and Physiological Determinants of Performance in French West Indian Monofin Swimmers: A First Approach," International Journal of Sports Medicine, Vol. 27, No. 8, 2006, pp. 605-609. http://dx.doi.org/10.1055/s-2005-865856

[11] R. H. Morton, J. R. Fitz-Clarke and E. W. Banister, "Modeling Human Performance in Running," Journal of Applied Physiology, Vol. 69, No. 3, 1990, pp. 1171-1177.

[12] R. E. Wood, S. Hayter, D. Rowbottom and I. Stewart, "Applying a Mathematical Model to Training Adaptation in a Distance Runner," European Journal of Applied Physiology, Vol. 94, No. 3, 2005, pp. 310-316. http://dx.doi.org/10.1007/s00421-005-1319-2

[13] E. W. Banister, T. W. Calvert, M. V. Savage and T. M. Batch, "A Systems Model of Training for Athletic Performance," Journal of Science and Medicine in Sport, Vol. 7, No. 3, 1975, pp. 57-61.

[14] I. Mujika, T. Busso, L. Lacoste, F. Barale, A. Geyssant and J. C. Chatard, "Modeled Response to Training and Taper in Competitive Swimmers," Medicine \& Science in Sports \& Exercise, Vol. 28, No. 2, 1996, pp. 251-258. http://dx.doi.org/10.1097/00005768-199602000-00015
[15] T. Busso, C. Carosso and J. R. Lacour, "Adequacy of a Systems Structure in the Modeling of Training Effects on Performance," European Journal of Applied Physiology, Vol. 61, No. 1-2, 1991, pp. 48-54.

http://dx.doi.org/10.1007/BF00236693

[16] T. Busso, K. Hakkinen, A. Pakarinen, C. Carasso, J. R. Lacour, P. V. Komi and H. Kauhanen, "A Systems Model of Training Responses and Its Relationships to Hormonal Responses in Elite Weight-Lifters," European Journal of Applied Physiology, Vol. 61, No. 1-2, 1990, pp. 48-54. http://dx.doi.org/10.1007/BF00236693

[17] J. C. Chatard, T. Busso, F. Barale and L. Lacoste, "Quantification et Modélisation de l'entraînement en Natation,"STAPS: Sciences et Techniques des Activités Physiques et Sportives, Vol. 33, 1994, pp. 7-17.

[18] P. Hellard, M. Avalos, L. Lacoste, F. Barale, J. C. Chatard and G. P. Millet, "Assessing the Limitations of the Banister Model in Monotoring Training," Journal of Sports Sciences, Vol. 24, No. 5, 2006, pp. 509-520. http://dx.doi.org/10.1080/02640410500244697

[19] T. Taha and S. G. Thomas, "Systems Modeling of the Relationship between Training and Performance," Sports Medicine, Vol. 33, No. 14, 2003, pp. 1061-1073. http://dx.doi.org/10.2165/00007256-200333140-00003

[20] E. W. Banister and C. L. Hamilton, "Variations in Iron Status with Fatigue Modeled from Training in Female Distance Runners," European Journal of Applied Physiology, Vol. 54, No. 1, 1985, pp. 16-23. http://dx.doi.org/10.1007/BF00426292

[21] E. W. Banister, J. B. Carter and P. C. Zarkadas, "Training Theory and Taper: Validation on Triathlon Athletes," European Journal of Applied Physiology, Vol. 79, No. 2, 1999, pp. 182-191. http://dx.doi.org/10.1007/s004210050493

[22] S. Le Bris, B. Ledermann, N. Topin, P. Messner-Pellenc and D. Le Gallais, "A Systems Model of Training for Patients in Phase 2 Cardiac Rehabilitation," International Journal of Cardiology, Vol. 109, No. 2, 2006, pp. 257263. http://dx.doi.org/10.1016/j.ijcard.2005.06.029

[23] G. P. Millet, A. Groslambert, B. Barbier, J. D. Rouillon and R. B. Candau, "Modelling the Relationships between Training, Anxiety, and Fatigue in Elite Athletes," International Journal of Sports Medicine, Vol. 26, No. 6, 2005, pp. 492-498. http://dx.doi.org/10.1055/s-2004-821137

[24] L. Thomas, I. Mujika and T. Busso, "A Model Study of Optimal Training Reduction during Pre-Event Taper in Elite Swimmers," Journal of Sports Science, Vol. 26, No. 6, 2008, pp. 643-652.

http://dx.doi.org/10.1080/02640410701716782

[25] K. Wasserman and M. B. Mcllroy, "Detecting the Threshold of Anaerobic Metabolism in Cardiac Patient during Exercise," American Journal of Cardiology, Vol. 14, No. 6, 1964, pp. 844-852. http://dx.doi.org/10.1016/0002-9149(64)90012-8

[26] K. Wasserman, B. J. Whipp, S. Koyal and W. L. Beaver, "Anaerobic Threshold and Respiratory Gas Exchange during Exercise," Journal of Applied Physiology, Vol. 35, No. 2, 1973, pp. 236-243.

[27] W. L. Beaver, K. Wasserman and B. J. Whipp, "A New 
Method for Detecting Anaerobic Threshold by Gas Exchange," Journal of Applied Physiology, Vol. 60, No. 6, 1986, pp. 2020-2027.

[28] D. M. McNair, M. Lorr and L. F. Droppleman, "Profile of Mood States Manual," Educational and Industrial Testing Service, San Diego, 1971.

[29] S. K. Seiler and ØG. Kjerland, "Quantifying Training Intensity Distribution in Elite Endurance Athletes: Is There Evidence for an 'Optimal' Distribution?" Scandinavian Journal of Medicine \& Science in Sports, Vol. 16, No. 1, 2006, pp. 49-56.

http://dx.doi.org/10.1111/j.1600-0838.2004.00418.x

[30] Y. Cherruault, "Modèles et Méthodes Mathématiques Pour les Sciences du Vivant," Presses Universitaires de France, 1998.

[31] B. O. Konfé, Y. Cherruault, B. Somé and T. Bennouala, "Alienor Method Applied to Operational Research," Kybernetes, Vol. 34, No. 7-8, 2005, pp. 1211-1222. http://dx.doi.org/10.1108/03684920510605984

[32] A. Lucia, J. Hoyos, M. Pérez and J. L. Chicharro, "Heart Rate and Performance Parameters in Elite Cyclists: A Longitudinal Study," Medicine \& Science in Sports \& Exercise, Vol. 32, No. 10, 2000, pp. 1777-1782. http://dx.doi.org/10.1097/00005768-200010000-00018

[33] R. Perini, C. Orizio, S. Milesi, L. Biancardi, G. Baselli and A. Veicsteinas, "Body Position Affects the Power Spectrum of Heart Rate Variability during Dynamic Exercise," European Journal of Applied Physiology, Vol. 66, No. 3, 1993, pp. 207-213. http://dx.doi.org/10.1007/BF00235095

[34] J. R. Lacour, "Biologie de L'Exercice Musculaire," Masson, Paris, 1992.

[35] I. M. Cockrill, A. M. Nevill and N. Lyons, "Modelling Mood States in Athletic Performance," Journal of Sports Science, Vol. 9, No. 2, 1991, pp. 205-212. http://dx.doi.org/10.1080/02640419108729881 